\title{
PCR-based HLA Class II Typing
}

\author{
Ulf Gyllensten and Marie Allen
}

\begin{abstract}
Department of Medical Genetics, University of Uppsala Biomedical Center,
\end{abstract} S-751 23 Uppsala, Sweden

\begin{abstract}
The human leukocyte antigen (HLA) class II molecules are cell-surface glycoproteins involved in the regulation of immune responses. Allelic variation at the HLA class II loci is an important consideration in major areas of medicine and biology. For instance, detailed knowledge of the allelic constitution at class II loci is required for matching of suitable donors and recipients for bone marrow and other tissue transplantations. Susceptibility to a number of autoimmune diseases has also been found to be associated with specific residues, alleles, or haplotypes at class II loci, ${ }^{(9-17)}$ and characterization of these loci provides an opportunity for early identification and initiation of immunotherapy for individuals at risk of developing these diseases. The class II polymorphism also provides an excellent marker system for paternity determinations and for purposes of individual identification in forensic medicine. ${ }^{(18,19)}$ Finally, these loci are valuable tools in determining evolutionary relationships at the DNA level. In this review we discuss the pros and cons of the alternate methods available for genetic typing of the allelic variation at class II loci for these various applications, using the polymerase chain reaction (PCR).
\end{abstract}

\section{HLA CLASS II LOCI}

A functional class II cell-surface antigen is composed of an $\alpha$ - and a $\beta$ chain and is capable of binding peptide fragments from processed antigens of foreign or endogeneous origin in a cleft formed by two $\alpha$-helices and a $\beta$ pleated sheet..$^{(1,2)}$ The bound peptide is recognized by the T-cell receptor in the context of the class II molecule, leading to T-lymphocyte activation.

The HLA class II region on chromosome 6 consists of the three subregions-DR, DQ and DP-each of which encodes one $\alpha$-chain and one, or, in the case of DR, several, $\beta$ chains. $^{(3,4)}$ The loci encoding these antigens are among the most polymorphic protein-coding genes in higher organisms..$^{(3-6)}$ The allele frequency distribution at most of the expressed HLA class II loci, with the exception of DPB1, is also signficantly different from that of most nuclear genes, with many alleles at intermediate frequencies. Most of the allelic sequence diversity resides in the second exon, which encodes the amino-terminal domain of the antigen..$^{(7,8)}$

\section{DETECTION OF HLA CLASS II POLYMORPHISM}

HLA typing was previously carried out exclusively with the use of serologic reagents or by studies of mixed lymphocyte culture (MLC) reactions. Although these assays are able to distinguish a number of the class II molecules, the technology is not sensitive enough to resolve the full spectrum of alleles. This is especially true for antigens such as the DP antigen, which is present in low abundance on the cell surface. When cDNA probes became available for the different loci, HLA typing could be carried out at DNA level by the restriction fragment length polymorphism method (RFLP), providing a somewhat finer resolution of the allelic variation. ${ }^{(20)}$

The introduction of the PCR meth$\mathrm{od}^{(21-23)}$ has made it possible to perform genetic typing of HLA class II loci by any of a number of alternate methods: heteroduplex analysis,(24) restriction enzyme cleavage analysis, $(22,25-27)$ allele-specific PCR amplification, ${ }^{(28,29)}$ oligonucleotide probe hybridization, ${ }^{(18,19,30-37)}$ and direct sequencing of amplification products. ${ }^{(28)}$ These alternate approaches are associated with different abilities to resolve the full allelic spectrum. Because they al- low identification of individual alleles independent of the relative levels of expression, the genotype can in most cases be determined unambiguously. Results similar to those of a null allele can be obtained if the two alleles in a heterozygous individual are amplified with different efficiencies. However, this phenomenon, named allelic dropout, has been noted only when the denaturation temperature in the PCR cycle is much below optimal temperatures (around $85^{\circ} \mathrm{C}$ and below) and does not normally occur when the standard temperature cycle is used.

\section{Heteroduplex Analysis}

A simple method for detecting genetic differences among individuals is heteroduplex analysis in which amplified material from two individuals is mixed, denatured, and reannealed and the heteroduplexes formed are examined on a native acrylamide gel.(24) Mismatches between the two products will result in the formation of heteroduplexes with a slower migration rate than products with perfectly matched strands. However, this method will not resolve the nature of the difference between alleles. Furthermore, it may be necessary to examine all possible combinations of individuals to find perfectly matched pairs. Therefore, each new individual for which a perfect match is sought either has to be tested against every individual in the donor population or against representatives of all known alleles. Consequently, because the typing results are difficult to compare between populations, this technique is not suited for typing of large international donor registers.

\section{PCR-RFLP}

The PCR-RFLP analysis technique is based on the amplification of DNA fragments from within a gene, or from flanking sequences, containing restric- 
tion sites specific to individual alleles. ${ }^{(22)}$ Sequence variations between two alleles can be identified by a restriction enzyme cleavage that creates products of different sizes. After digestion of the amplified fragments, the products are examined by agarose gel electrophoresis. This method requires the identification of RFLPs unique to each allele, and is likely to require the use of multiple pairs of $P C R$ primers. In addition, the screening systems require for correct typing that restriction enzyme cleavages are not inhibited. This method is essentially a simplified version of general RFLP, and because the restriction site used for diagnosis may not reside within the gene, actual coding sequence information will not be obtained. Consequently, new polymorphisms arising within the framework of flanking restriction sites may be missed. This method has been used to type alleles or groups of alleles at the DPB1, (25) DRB1, and DQB1 loci. ${ }^{(26)}$ Due to the lack of RFLP patterns unique to every allele, this approach fails to distinguish many of the genotypes at class 11 loci. (27)

\section{Allele-specific PCR Amplification}

The PCR reaction itself can be done in an allele-specific manner by designing one, or both, of the PCR primers with a sequence complementary to that of a specific allele. With the proper PCR annealing temperature, the oligonucleotides will prime a single type of allele exclusively, and thus result in an amplification product only if that specific allele is present in the sample. ${ }^{28,29)}$

The main advantage of this method is that typing results can be obtained simply by examining the products by gel electrophoresis. However, this is also the drawback of the method because the number of parallel reactions needed equals that of the complete set of alleles. In fact, as a total of almost 100 different alleles are known at the most common target loci (DQA1, DQB1, DRB1, DPB1; Table 1), many primer pairs have to be designed and optimized, and even if a number of multiplex PCRs are composed, the number of parallel reactions of the same DNA is likely to be large. The technique has, however, proven useful for the analysis of individual alleles, when the composite oligonucleotide typing does not result in an unambiguous allelic designation. In addition, it can be applied to the subtyping of the various DR types. ${ }^{(36,37)}$

Allele-specific PCR amplification is also useful in forensic medicine when the biological evidence material contains a mixture of genotypes. ${ }^{(38)}$ Such samples are common in the analysis of vaginal swabs from rape cases, where most of the genetic material originates from the epithelial cells of the victim and only trace amounts of genetic material are derived from the sperm cells of the rapist.

\section{Oligonucleotide Typing of Amplified Products}

The use of short, nonradioactively labeled probes to type PCR-amplified DNA is a simple and rapid method to detect allelic sequence variation at the HLA class II genes. By using primers complementary to regions of the second exon that are conserved among all alleles, most of the polymorphism at class II loci can be detected (Table 1). ${ }^{(18,19,30-37)}$

For typing, the amplified samples are hybridized to allele-specific (ASO) or sequence-specific oligonucleotides (SSO) that under the proper hybridization and washing conditions will form stable heteroduplexes only with those sequences to which they are complementary. ${ }^{(22)}$ The short length of the probes will cause even a single base mismatch to destabilize the heteroduplex significantly. At many class II loci, the polymorphic motifs defined by these oligonucleotides are shared between several alleles, and the probes are therefore sequence-specific rather than allele-specific. An allele is identified by the pattern of hybridization of a series of oligonucleotide probes.

Two formats have been developed for detection of a stable heteroduplex between oligonucleotide probe and PCR product (Fig. 1). In the first typing format, the amplified DNA sample is immobilized on a nylon membrane and horseradish peroxidase (HPR)labeled probes are hybridized to the PCR products. As an alternative, biotin-labeled probes can be used, to which HRP is attached by incubating the membrane with streptavidin-HRP. The bound probe can be detected with an enhanced chemiluminescence
(ECL) system (Amersham) or by the conversion of the colorless soluble tetramethylbenzidine (TMB) into a colored precipitate (Fig. 1).

Alternatively, in the "reverse dot blot" format, the oligonucleotide probes are immobilized on the membrane and hybridized to a biotinylated PCR product. ${ }^{(31)}$ The probes immobilized on the membrane are tailed with poly $(\mathrm{dT})$ using terminal transferase and then cross-linked to the membrane by UV irradiation. (31) Biotinylation of the PCR product is achieved by attaching a biotin molecule to the $5^{\prime}$ end of one of the PCR primers. PCR products hybridizing to the probe are detected using a streptavidin-HRP conjugate that is used either to convert TMB or can be detected with the $\mathrm{ECL}$ system.

These non radioactive detection systems have several advantages over classical radioactive dot blots. In addition to being rapid, economic, and not associated with the precautions and constraints associated with the use of radioisotopes, the somewhat lower levels of sensitivity result in less problems with cross-hybridization. The nonradioactively labeled probes can be stored for years and it is possible to reuse the hybridization solutions as well as membranes. The ECL detection system is faster than using TMB, more sensitive, and allows for an easier reuse of the membranes.

Oligonucleotide probe-based typing of PCR-generated fragments offers the highest resolving power of the different methods previously discussed. The typing results are not significantly affected by the errors inherent in the PCR, such as point mutational errors or recombinant products. ${ }^{(23,31)}$ The main advantage is, however, that the coding sequence is the target for typing rather than linked polymorphisms. This will allow identification of polymorphic residues that are critical to disease susceptibility, graft rejection in transplantations, antigen presentation, and $T$ cell recognition. Under certain conditions, the oligonucleotide typing system will also allow identification of previously unidentified alleles. The need to handle large numbers of individual probes with different melting temperatures has limited the clinical usefulness of typing of immobilized PCR products (format 1 in Fig. 1). 
TABLE 1 Allelic Resolution with Oligonucleotide Typing of HLA Class II Genes

\begin{tabular}{lcccc}
\hline Class II locus & PCR primers & Number of known alleles & Number of probes used in typing & Resolved alleles \\
\hline DQA1 & GH26/GH27 & 13 & 8 & 6 \\
DQB1 & DB130/DB131 & 17 & 15 & 15 \\
DPB1 & UG19/UG21 & 21 & 15 & 19 \\
DRB1 & CRX37/GH46/GH50 & 47 & 25 & 39 \\
\hline
\end{tabular}

Sources: refs. $19,22,23$, and 25 .

When membranes for reverse dot blot hybridization become available for all class II loci, PCR-based typing will also be possible in laboratories with limited experience in molecular biology.

The only drawback with this, as well as with many other HLA-typing techniques, is that for certain genotypes the individual alleles may not be possible to resolve. In the dot blot typing system, individual alleles are deduced from the hybridization pattern of probes and the allelic phase of different polymorphic regions is not known. As a result, the most likely allelic constitution can be inferred only when the complete spectrum of alleles is known. Because additional alleles are being found at some of the loci (i.e., DRB1, DPB1), the typing results for certain allelic combinations will continue to be uncertain. Even when all alleles are known, some genotypes will result in combinations of polymorphic regions whose allelic phase cannot be determined. For example, the DRB1 genotypes $1301 / 0408$ and $1302 / 0404$ will give identical typing results using a series of six oligonucleotide probes made to three different polymorphic regions in the second exon (Fig. 2). Thus, while the number of known alleles will increase, as will the number of probes used to identify them, the number of alleles that can be distinguished, may in fact, decrease somewhat (Table 1). This results from the fact that many of the new alleles appear to have been generated by combining variants already present in other alleles. The frequency of individuals with such genotypes will, however, in most populations only constitute less than $1 \%$. One solution to this potential problem is to perform allele-specific amplification of those individuals where the allelic phase of the polymorphism cannot be resolved by typing. ${ }^{(29,39,40)}$ Also, since the DQ and DR genes are in strong linkage disequilibrium, the allelic contribution of neighboring loci may be inferred by constructing putative haplotypes.

\section{Direct Sequencing of PCR Products}

Sequencing of amplified DNA gives the highest resolution of all typing methods, but because of the associated cost and time effort it is unlikely to become the diagnostic method of choice for routine analysis. A variety of alternate methods are available for generating either double-stranded or singlestranded templates from PCR products for manual or automated DNA sequencing using the Sanger method with chain terminators. ${ }^{(28,41)}$ The main drawback with direct sequencing of HLA class II genes as a diagnostic method is the high heterozygosity at most loci. Due to the large number of mutational differences between any

\section{FORMAT I}

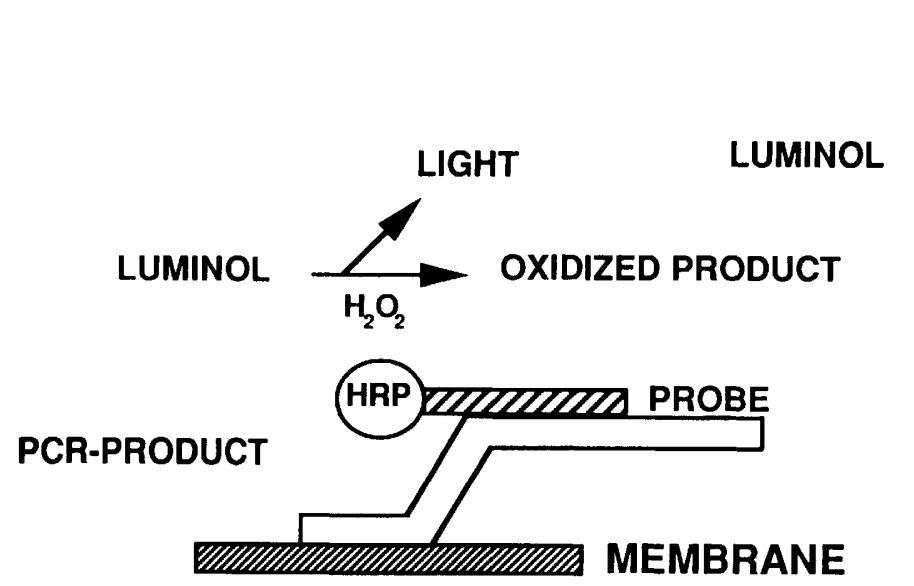

FORMAT II

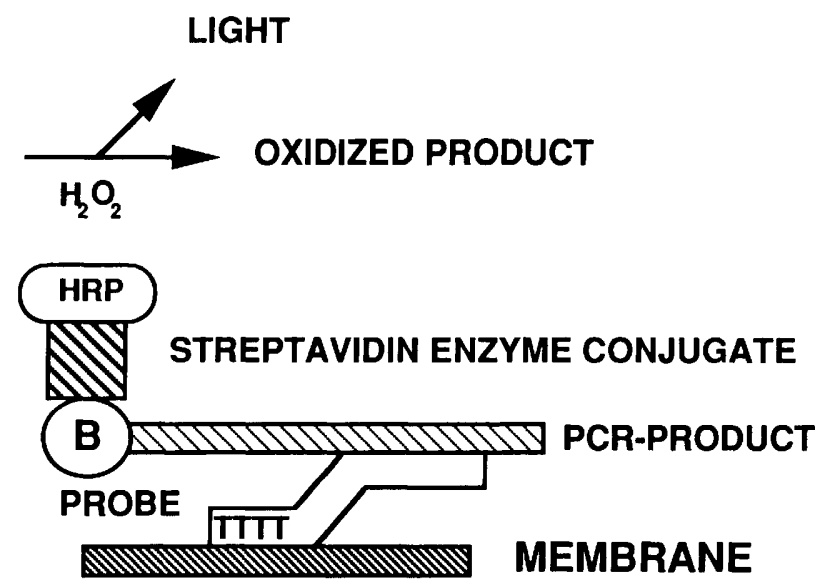

FIGURE 1 Schematic representation of two strategies for detection of oligonucleotide hybridization. 
ALLELES
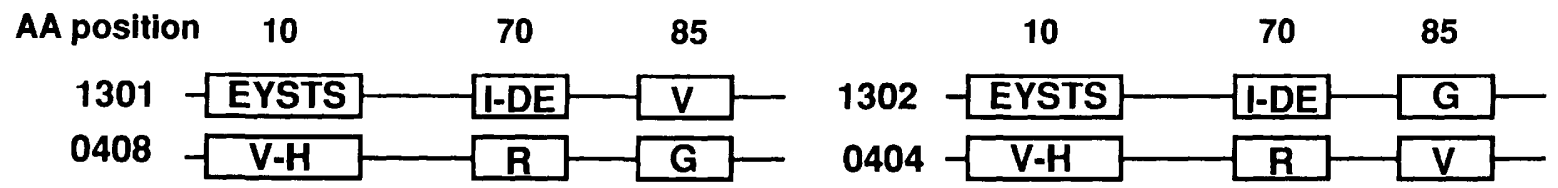

Probes

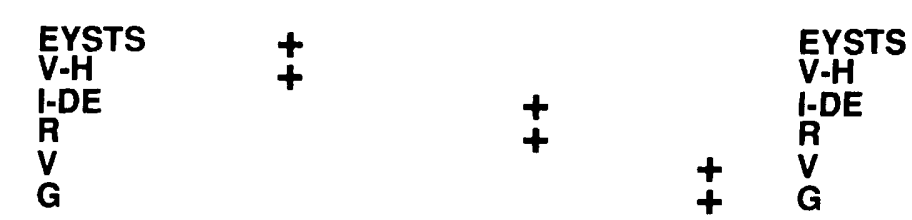

TYPING RESULTS

FICURE 2 Results of oligonucleotide typing of the two genotypes DRB1 1301/0408 and 1302/0404 that cannot be distinguished using a set of six different probes. Due to the sharing of polymorphic motifs between alleles, the combination of motifs on individual alleles cannot be determined without allele-specific amplification and subsequent typing.

two HLA alleles including the presence of small deletions or insertions, the sequence ladders generated from heterozygous individuals will contain multiple heterozygous positions whose allelic phase is unknown. (28)

There are several ways to resolve the phase of individual mutations and obtain sequences of individual alleles from heterozygote individuals that can be applied prior to, during, or after the PCR. First, the PCR products may be separated on the basis of their nucleotide sequence prior to sequencing using a formamide gradient gel electrophoresis (DGGE) or a temperature-gradient gel electrophoresis system (TGGE). ${ }^{(42,43)}$ After electrophoresis, the different allelic templates are excised from the gel, reamplified, and sequenced individually. This procedure requires no prior knowledge about the alleles. However, if some information is available for the range of possible alleles, individual alleles may be amplified by using allele-specific primers, (28) or may be primed individually in the sequencing reaction. ${ }^{(28)}$ The later approach requires the use of Taq polymerase as the sequencing enzyme to yield sufficient specificity in the priming.

\section{USE OF HLA TYPINC}

HLA and Transplantation

The most important application of
PCR-based HLA typing is for selection of matched donor and recipient pairs to avoid rejection in tissue transplantations. ${ }^{(44,45)}$ Recent studies indicate that the 1-year transplant success rate can be increased by about $20 \%$ when the graft choice is based on DNA-RFLP matching, rather than serological typing alone, and matching based on typing of PCR products is likely to yield an even higher success rate, most notably by lowering the long-term rejection rate. ${ }^{(45)}$ The higher resolution offered by DNA typing will in effect make it more unlikely to obtain completely matched local pairs, unless close relatives are available. Therefore, the efforts to create national and international registers of completely HLAtyped bone marrow and other tissue donors are exceedingly important. Such registers will find a number of uses, including being a potential source of donors for certain categories of gene therapy. However, even among these large collections of donors perfect matches for both class I and class II genes may be difficult to find. Today transplantations are performed de facto in the face of unknown mismatches due to the lack of proper typing technology. With a complete typing system, donors can be selected more optimally, and the precise impact of individual mismatches on graft survival rate can be determined.

\section{Class II-associated Diseases}

More than 40 diseases have been found to be associated with particular class II haplotypes. In many of these diseases the presence of a certain allele strongly associated with the disease is not enough to explain disease development, since only some of the individuals who carry this allele or haplotype will develop the disease. Thus, at present it cannot be excluded either that the class II variants act as genetic markers in linkage disequilibrium with other putative disease susceptibility alleles that predispose to the disease, or that additional factors such as viral infections are necessary for the development of the disease.

Nevertheless, PCR-based analysis has had a major influence upon our understanding of the molecular basis for autoimmunity. First, the ease by which new allelic sequences can be generated has resulted in the identification of individual residues postulated to confer susceptibility or resistance to some of the most important autoimmune diseases. $(5,6,9,17,46,47)$ In other cases, it has been suggested that the whole allele or the heterodimer is the cause of the autoimmune reaction. ${ }^{(11)}$ Second, PCR has made possible the analysis of the T-cell repertoire in key cell types. ${ }^{(48)}$ Thus, a combined analysis of the variation in the two molecules responsible for the 
antigen recognition process is possible, potentially providing new insight into the mechanism by which autoimmunity is triggered. Pending future developments in the field of immunotherapy, individuals at risk of developing autoimmune symptoms may be identified at an early stage, thereby making it possible to delay or completely reverse the autoimmune process.

\section{HLA Typing in Forensics}

The HLA class II loci provide a suitable set of markers for the typing of biological evidence material secured from the crime scene. Conventional VNTR or "DNA fingerprint" technologies require from hundreds of nanograms to microgram amounts of DNA to be useful, whereas PCR is applicable to samples with less than a nanogram of DNA. Indeed, many of the biological evidence materials, such as single hairs, small blood stains, small amounts of semen mixed with vaginal fluids and epithelial cells, bits of bone, and tissue from under fingernails are too limited to be analyzed by conventional DNA analysis. ${ }^{(19,49,50)}$

The DNA markers most commonly used for forensic analysis, such as single VNTR loci or multilocus patterns (minisatellite), have very high discriminatory powers. ${ }^{(51)}$ However, these systems are relatively evolutionarily unstable and the repetitive nature of the sequences may result in the accumulation of artifact products caused by off-register reannealing of PCR products. ${ }^{(52)}$ By contrast, the HLA class I and II loci, as well as other single-copy coding sequences, have a number of defined and stable alleles. Thus, typing of PCR products using oligonucleotide probes is possible using even very degraded DNA samples. All erroneous PCR products are excluded by dot blot typing, and products resulting from nonspecific priming or priming of highly degraded DNA copies do not usually interfere, resulting in an unambiguous typing of the DNA even when the target products constitute a minor fraction of all PCR products. An example of the use of HLA typing employing the typing system for the HLA-DQA1 locus is shown in Figure 3. In this case, two men were suspected of having raped a woman (victim), and
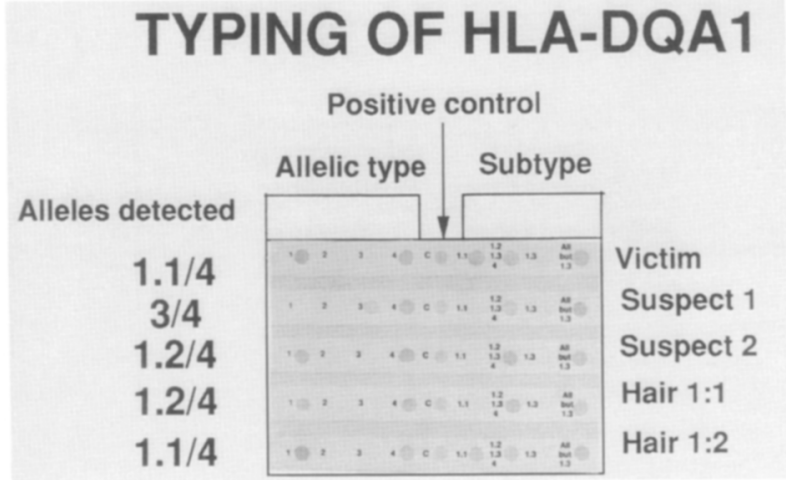

FICURE 3 Results of HLA-DQA1 typing of the biological evidence from a criminal case (see text for details).

the evidence consisted of two individual hairs found on the victim. The DQA1 locus typing revealed that evidence hair number 1:2 could not have come from any of the two suspects but may be derived from the victim herself. Evidence hair number 1:1 could not have come from the victim herself, but was found to contain alleles identical to those of one of the suspects. The relatively low power of discrimination of the DQA1 locus by itself results in a probability of identity by chance for the genotype of hair $1: 1$ of about $11 \%$ in a Swedish population. However, by similar analysis of several class I and class II loci, this probability can be reduced substantially.

\section{Evolutionary Analysis of HLA Polymorphism by PCR}

PCR provides the most powerful technique so far developed for studying the evolutionary process of different taxa at the DNA level. Oligonucleotide primers based on the sequence of regions of the DNA that are conserved or evolving at a normal rate have successfully been applied to comparative analysis of the homologous gene in species that have been isolated for 40-80 million years. ${ }^{(53-56)}$ For instance, the primers made to human sequences have been used to study homologous gene segments from Old and New World monkeys. Also, PCR based on degenerate primers has been used to clone the first representatives of Mhc genes from fishes, something that had been proven impossible using conventional DNA technology. ${ }^{(57)}$

The evolutionary origin and maintenance of the extensive allelic diversity at HLA class II loci has been the subject of considerable controversy. (58-62) Two hypotheses have been advanced to explain the origin of sequence polymorphism: Either the polymorphism has been generated during the lifetime of the human species, or, alternatively, it could predate speciation and may have been maintained in the contemporary human population by selection. Comparsion of the allelic spectrum in humans with that in other hominoids has revealed striking similarities between allelic types found in different primates. ${ }^{(53-56,63,64)}$ Phylogenetic analysis of allelic sequences at the DQA1 locus has shown that the four major allelic types found in man have counterparts in several hominoids (Fig. 4). For example, representatives of sequences of the A1 allelic type are found in all the hominoids (human, gorilla, chimpanzee) examined. The similarity of allelic types between species is evident both from analysis of the amino acid sequences and the silent changes, indicating that the allelic types predate the hominoid divergence, that some predate even the divergence of Old World monkeys, and that the similarities are not due to convergent evolution of unrelated sequences. Similarly, alleles at the DQB1, and DRB1 have been analyzed for their evolutionary antiquity; ${ }^{(55,56)}$ the results indicate that many of the allelic types may be 5-20 million years old. In some cases, the polymorphism is so conserved that oligonucleotides made to human alleles can be used for typing of samples from other hominoids (Gyllensten et al., in prep.).

\section{FUTURE DEVELOPMENTS}

The availability of a complete PCR- 


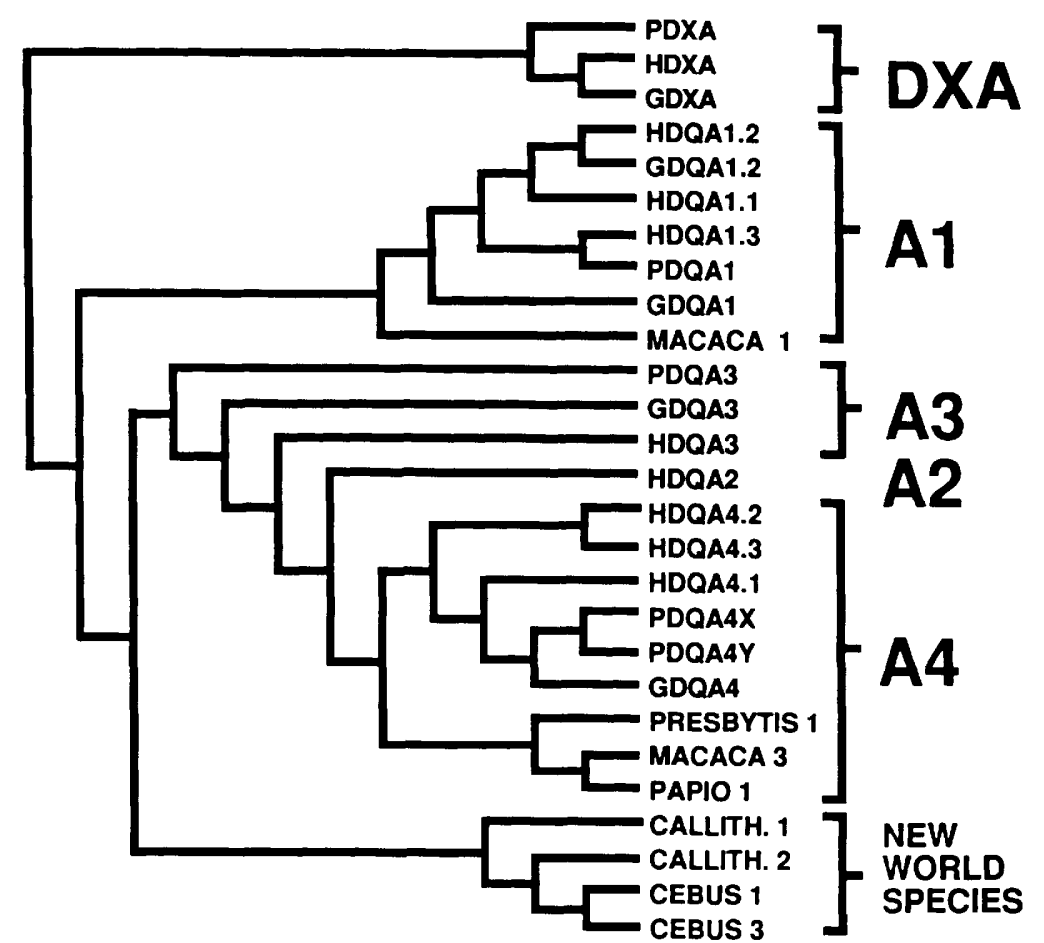

FIGURE 4 Phylogenetic tree for alleles at the HLA-DQA1 locus from different primates. (For details on the analysis, see ref. 53.) The sequences representing different allelic forms are bracketed in the tree. The sequences HDXA, HDQA1.2, HDQA1.1, HDQA1.3, HDQA2, HDQA3, HDQA4.1, HDAQ4.2, and HDQA4.3 are derived from humans. The sequences PDXA, PDQA1, PDQA3, PDQA4X, and PDQA4Y are derived from regular chimpanzee. The sequences GDXA, GDQA1.2, GDQA1, GDQA3, and GDQA4 are derived from gorilla. The other sequences are derived from other Old World (Macaca, Presbytis, Papio) or New World (Callithrix, Cebus) monkeys.

based typing system for the class Ii genes will stimulate interest in applying the same technology for detailed typing of the polymorphism in the class I region. However, the development of a PCR-based system for the class I loci $\mathrm{A}, \mathrm{B}$, and $\mathrm{C}$ represents an unprecedented challenge from both a theoretical and a practical standpoint. First, the high homology between the three genes will hinder the designation of locus-specific amplification systems. ${ }^{(65,66)}$ If a single primer pair is used for the amplification of all three loci, the typing result may be hard to interpret. This is because the tendency for exchange of sequence elements between exons from the same locus, or even between loci, will severely hinder an unambiguous assignment of polymorphic residues to a specific locus and exon. ${ }^{(67)}$ Third, the distribution of polymorphism at class I loci which span over several exons, instead of a single exon as in the class II loci, will result in some uncertainty with regard to the allelic phase of the polymorphism in the different exon. Finally, al- though there has been rapid progress toward a more complete picture of the allelic spectrum at class I loci, new alleles will for some time continue to be uncovered and cause some uncertainty in the genetic typing. Nevertheless, attempts are underway to develop partial $^{(68)}$ and complete class 1 typing systems, and the availability of complete class II typing systems will undoubtably inspire further initiatives.

There is also a need for further development of the typing format. With an ever-increasing complexity in the number of polymorphic regions and probes to survey, the results of the dot blot analysis will have to be read automatically. One possibility is to design the typing format so that the readout will mimic the bar codes commonly used for automatic identification of products. This line of development will focus on the needs of smaller laboratories that perform rapid analysis of small numbers of individuals. For laboratories with high throughput, alternate methods for DNA diagnostics, such as the oligonucleotide ligation as- say(69) or the ligation chain reaction, may be more suitable. These technologies could be combined with a flouorescent readout that will enable the design of a completely automated system for typing.

PCR-based typing has already provided new insight into the intriguing complexity of the polymorphism at class II loci and its evolutionary antiquity. While the perfect typing system still needs to be developed, available systems for oligonucleotide typing are able to resolve most allelic variants and have already pushed the resolution of the typing technology to unsurpassed levels.

\section{ACKNOWLEDGMENT}

U.G. was supported by a fellowship from the Knut and Alice Wallenberg Foundation and a grant from the Swedish Natural Science Resarch Council.

\section{REFERENCES}

1. Bjorkman, P.J., M.A. Saper, B. Samraoui, W.S. Bennett, J.L. Strominger, and D.C. Wiley. 1987. Structure of the human class I histocompatibility antigen HLA-A2. Nature 329: 506-512.

2. Brown, J.H., T. Jardetzky, M.A. Saper, B. Samaraoui, P.J. Bjorkman, and D.C. Wiley. 1988. A hypothetical model of the foreign antigen binding site of class II histocompatibility molecules. Nature 332: 845-850.

3. Trowsdale, J., J.A.T. Young, A.P. Kelly, P.J. Austin, S. Carson, H. Meunier, A. So, H.A. Erlich, R. Spielman, J. Bodmer, and W.F. Bodmer. 1985. Structure sequence and polymorphism in the HLA-D region. Immunol. Rev. 85: 5-43.

4. Kappes, D. and J.L. Strominger. 1988. Human class 11 major histocompatibility complex genes and proteins. Annu. Rev. Biochem. 57: 991-1028.

5. Horn, G.T., T.L. Bugawan, C. Long, and H.A. Erlich. 1988. Allelic variation of HLA-DQ loci: Relation to serology and to insulin-dependent diabetes susceptibility. Proc. Natl. Acad. Sci. 85: 6012-6016.

6. Todd, J.A., J.I. Bell, and H.O. McDevitt. 1987. HLA-DQb gene contributes to susceptibility and resistance to insulin-dependent diabetes mellitus. Nature 329: 599-604.

7. Bodmer, J.G., S.G.E. Marsh, E.D. 
Albert, W.F. Bodmer, B. Dupont, H.A. Erlich, B. Mach, W.R. Mayr, P. Parham, T. Sasazuki, G.M.T. Schreuder, J.L. Strominger, A. Svejgaard, and P.I. Terasaki. 1991. Nomenclature for factors of the HLA system, 1990. Tissue Antigens 37: 97-104.

8. Marsh, S.G.E. and J.G. Bodmer. 1991. HLA Class II nucleotide sequences, 1991. Tissue Antigens 37: 181-189.

9. Scharf, S., A. Friedman, C. Brautbar, F. Szafer, L. Steinman, G. Horn, U. Gyllensten, and H.A. Erlich. 1988. HLA class II allelic variation and susceptibility to pemphigus vulgaris. Proc. Natl. Acad. Sci. 85: 3504-3508.

10. Sinha, A.A., C. Brautbar, F. Szafer, A. Friedman, E. Tzfoni, J.A. Todd, J.I. Bell, and H.O. McDevitt. 1988. A newly characterized HLA-DQb allele associated with Pemphigus vulgaris. Science 239: 1026-1029.

11. Bugawan, T.L., G. Angelini, J. Larrick, S. Auricchio, G.B. Ferrara, and H.A. Erlich. 1988. A combination of a particular HLA-DP $\beta$ allele and an HLA-DQ heterodimer confers susceptibility to coeliac disease. Nature 339: 470-473.

12. Begovich, A., T.L. Bugawan, G. Nepom, W. Klitz, B. Nepom, and H.A. Erlich, 1989. A specific HLA-DP $\beta$ allele is associated with pauciarticular juvenile rheumatoid arthritis but not adult rheumatoid arthritis. Proc. Natl. Acad. Sci. 86: 9489-9493.

13. Scharf, S.J., A. Friedman, L. Steinman, C. Brautbar, and H.A. Erlich. 1989. Specific HLA-DQ $\beta$ and HLA-DR $\beta 1$ alleles confer susceptibitity to Pemphigus vulgaris. Proc. Natl. Acad. Sci. 86: 6215-6219.

14. Jeannet, M. 1986. Class II HLA antigens in autoimmune and immune-mediated diseases. In $H L A$ class II antigens (ed. B.G. Solheim, E. Moller, and S. Ferrone), pp. 489--515. Springer-Verlag, Berlin.

15. Ronningen, K.S., A. Spurkland, T. Iwe, F. Vartdal, and E. Thorsby. 1991. Distribution of HLA-DRB1, -DQA1 and DQB1 alleles and DQA1 -DQB1 genotypes among Norwegian patients with insulin-dependent diabetes mellitus. Tissue Antigens 37: 105-111.

16. Baisch, J.M., T. Weeks, R. Giles, M. Hoover, P. Stastny, and J.D. Capra. 1990. Analysis of HLA-DQ genotypes and susceptibility in insulin- dependent diabetes mellitus. N. Engl. J. Med. 332: 1836-1841.

17. Todd, J.A., H. Acha-Orbea, J.I. Bell, N. Chao, Z. Fronek, C.O. Jacob, M. McDermott, A.A. Sinha, L. Timmermann, L. Steinman, and H.O. McDevitt. 1988. A molecular basis for MHC class II associated autoimmunity. Science 240: 1003-1009.

18. Bugawan, T.L., R.K. Saiki, C.H. Levenson, R.M. Watson, and H.A. Erlich. 1988. The use of nonradioactive oligonucleotide probes to analyze enzymatically amplified DNA for prenatal diagnosis and forensic HLA typing. Biotechnology 6: 943-947.

19. Higuchi, R., C.H. von Beroldingen, G.F. Sensabaugh, and H.A. Erlich. 1988. DNA typing from single hairs. Nature 332: 543-546.

20. Erlich, H.A., E.L. Sheldon, and G. Horn. 1986. HLA typing using DNA probes. Biotechnology 4: 975-981.

21. Mullis, K.B. and F. Faloona. 1987. Specific synthesis of DNA in vitro via a polymerase catalyzed chain reaction. Methods Enzymol. 155: 335-350.

22. Saiki, R., S. Scharf, F. Faloona, K. Mullis, G. Horn, H.A. Erlich, and N. Arnheim. 1985. Enzymatic amplification of $\beta$-globin genomic sequences and restriction site analysis for diagnosis of sickle cell anemia. Science 230: 1350-1354.

23. Saiki, R.K., D.H. Gelfand, S. Stoffel, S. Scharf, R. Higuchi, G. Horn, K.B. Mullis, and H.A. Erlich. 1988. Primerdirected enzymatic amplification of DNA with a thermostable DNA polymerase. Science 329: 487-491.

24. Clay, T.M., J.L. Bidwell, M.R. Howard, and B.A. Bradley. 1991. PCR-fingerprinting for selection of HLA matched unrelated marrow donors. Lancet 337: 1049-1052.

25. Maeda, M., N. Uryu, N. Murayama, H. Ishii, M. Ota, K. Tsuji, and H. Inoko. 1990. A simple and rapid method for HLA-DP genotyping by digestion of PCR amplified DNA with allele-specific restriction endonucleases. Hum. Immunol. 27: 111-121.

26. Uryu, N., M. Maeda, M. Ota, K. Tsuji, and $\mathrm{H}$. Inoko. 1990. A simple and rapid method for HLA-DRB and -DQB typing by digestion of PCR-amplified DNA with allele specific restriction endonucleases. Tissue Antigens 35: 20-31.
27. Olerup, O. 1990. HLA class II typing by digestion of PCR-amplified DNA with allele-specific restriction endonucleases will fail to unequivocally identify the genotypes of many homozygous and heterozygous individuals. Tissue Antigens 36: 83-87.

28. Gyllensten, U. and H.A. Erlich. 1988. Generation of single-stranded DNA by the polymerase chain reaction and its application to direct sequencing of the HLA-DQA locus. Proc. Natl. Acad. Sci. 85: 7652-7656.

29. Fernandezvina, M., M.E. Moreas, and P. Stastny. 1991. DNA typing for class-II HLA antigens with allelespecific or group-specific amplification. 3. Typing for 24 alleles of HLADP. Human lmmunol. 30: 60-68.

30. Saiki, R.K., T.L. Bugawan, G.T. Horn, K.B. Mullis, and H.A. Erlich. 1986. Analysis of enzymatically amplified $\beta$-globin gene and HLA-DQa DNA with allele-specific oligonucleotide probes. Nature 324: 163-166.

31. Saiki, R.K., P.S. Walsh, C.H. Levenson, and H.A. Erlich. 1989. Genetic analysis of amplified DNA with immobilized sequence-specific oligonucleotide probes. Proc. Natl. Acad. Sci. 86: 6230-6234.

32. Bugawan, T.L., G.T. Horn, C.M. Long, E. Mickelson, J.A. Hansen, G.B. Ferrara, G. Angelini, and H.A. Erlich. 1988. Analysis of HLA-DPB allelic sequence polymorphism using the in vitro enzymatic DNA amplification of $\mathrm{DP} \alpha$ and DP $\beta$ loci. J. Immunol. 141: 4024-4030.

33. Bugawan, T.L., A.B. Begovich, and H.A. Erlich. 1990. Rapid HLA DPB typing using enzymatically amplified DNA and non-radioactive sequencespecific oligonucleotide probes. Immunogenetics 32: 231-241.

34. Bugawan, T.L. and H.A. Erlich. 1991. Rapid typing of HLA-DQB1 DNA polymorphism using non-radioactive oligonucleotide probes and amplified DNA. Immunogenetics 33: 163-170.

35. Scharf, S.J., R.L. Griffith, and H.A. Erlich. 1991. Analysis of DNA sequence polymorphism at the HLADRB1 locus using the polymerase chain reaction and non-radioactive oligonucleotide probes. Hum. Immunol. 190-201.

36. Vaughan, R.W., J.S.S. Lanchbury, S.G.E. March, M.A. Hall, J.G. Bodmer, and K.I. Welsh. 1990. The application 
of oligonucleotide probes to HLA class II typing of the DRB sub-region. Tissue Antigens 36: 149-155.

37. Petersdorf, E.W., A.G. Smith, E.M. Mickelson, P.J. Martin, and J.A. Hansen. 1991. Ten HLA-DR4 alleles defined by sequence polymorphism within the DRB1 first domain. Immunogenetics 33: 267-275.

38. Gyllensten, U.B., A. Josefsson, K. Schemschat, T. Saldeen, and U. Petterson. 1991. DNA typing of forensic material with mixed genotypes using allele-specific enzymatic amplification (PCR) (submitted).

39. Wordsworth, P.B., C.E.M. Allsopp, R.P. Young, and J.I. Bell. 1990. HLADR typing using DNA amplification by the polymerase chain reaction and sequential hybridization to sequencespecific oligonucleotide probes. $l \mathrm{~m}$ munogenetics 32: 413-418.

40. Fugger, L., L.P. Ryder, N. Morling, N. Ödum, J. Friis, F.K. Pedersen, C. Hellmann, M. Sandberg-Wollheim, and A. Svejgaard. 1990. DNA typing for HLA-DPB $1{ }^{\star} 02$ and DPB $1^{\star} 04$ in multiple sclerosis and juvenile rheumatoid arthritis. Immunogenetics 32: $150-156$.

41. Gyllensten, U. 1989. PCR and DNA sequencing. Biotechniques 7: 700-708.

42. Fisher, S.G. and L.S. Lerman. 1983. DNA fragments differing by single base-pair substitutions are separated in denaturing gradient gels: Correspondence with melting theory. Proc. Natl. Acad. Sci. 80: 1579.

43. Myers, R.M., V.C. Sheffield, and D.R. Cox. 1988. Detection of single base changes in DNA: Ribonuclease cleavage and denaturation gradient gel electrophoresis. In Genome analysis: A practical approach (ed. K.E. Davies), pp. 95-141. IRL Press, Oxford.

44. Ting, A. 1986. The role of HLA class II antigens in clinical transplantation. In HLA class II antigens (ed. B.G. Solheim, E. Möller, and S. Ferrone) pp. 515-529. Springer-Verlag, Berlin.

45. Opelz, G., J. Mytilineos, S. Schever, H. Dunckley, J. Trejaut, J. Chapman, D. Middleton, D. Savage, O. Fisher, J.-D. Bignon, J.-C. Bensa, E. Albert, and $\mathrm{H}$. Noreen. 1991. Survival of DNA HLADR typed and matched cadaver kidney transplants. Lancet 338: 461-463.

46. Vartdal, F., L.M. Sollid, B. Vandvik, G. Markussen, and E. Thorsby. 1989.
Patients with multiple sclerosis carry DQB1 genes which encode shared polymorphic amino acid sequences. Hum. Immunol. 25: 103-110.

47. Spurkland, A., K.S. Ronningen, B. Vandvik, E. Thorsby, and F. Vartdal. 1991. HLA-DQA1 and HLA-DQB1 genes may jointly determine susceptibility to develop multiple sclerosis. Hum. Immunol. 30: 69-75.

48. Oksenberg, J.R., S. Stuart, A.B. Begovich, R.B. Bell, H.A. Erlich, L. Steinmann, and C.C.A. Bernard. 1990. Limited heterogenetity of rearranged T-cell receptor Va transcipts in brains multiple sclerosis patients. Nature 345: 344-346.

49. Pääbo, S., J.A. Gifford, and A.C. Wilson. 1988. Mitochondrial DNA sequences from a 7000-year old brain. Nucleic Acids Res. 16: 9775-9787.

50. Pääbo, S., R.G. Higuchi, and A.C. Wilson. 1989. Ancient DNA and the polymerase chain reaction. The emerging field of molecular archaeology. J. Biol. Chem. 264: 9709-9712.

51. Jeffreys, A.J., V. Wilson, and S.L. Thein. 1985. Hypervariable "minisatellite" regions in human DNA. Nature 314: 67-73.

52. Jeffreys, A.J., V. Wilson, R. Neumann, and J. Keyte. 1988. Amplification of human minisatellites by the polymerase chain reaction: Towards DNA fingerprinting of single cells. Nucleic Acids Res. 16: 10953-10971.

53. Gyllensten, U. and H.A. Erlich. 1989. Ancient roots for polymorphism at the DQa locus of primates. Proc. Natl. Acad. Sci. 86: 9986-9990.

54. Gyllensten, U., D. Lashkari, and H.A. Erlich. 1990. Allelic diversification at the class II DQB locus of the mammalian major histocompatibility complex. Proc. Natl. Acad. Sci. 87: 1835-1839.

55. Gyllensten, U., M. Sundvall, and $H$. Erlich. 1991. Allelic diversity is generated by intra-exon exchange at class II Mhc DRB1 locus of primates. Proc. Natl. Acad. Sci. 88: 3686-3690.

56. Gyllensten, U., M. Sundvall, I. Ezcurra, and H.A. Erlich. 1991. Genetic diversity at class II DRB loci of the primate histocompatibility complex. I. Immunol. 146: 4368-4376.

57. Hashimoto, K., T. Nakanishi, and Y. Kurosawa. 1990. Isolation of carp genes encoding major histocompati- bility complex antigens. Proc. Natl. Acad. Sci. 87: 6863-6867.

58. Figueroa, F., E. Günther, and J. Klein. 1988. Mhc polymorphism predating speciation. Nature 335: 265-268.

59. Klein, J. and F. Figueroa. 1986. Evolution of the major histocompatibility complex. CRC Crit. Rev. Immunol. 6: 295-386.

60. McConnelI, T.J., W.S. Talbot, R.A. Mclndoe, and E.K. Wakeland. 1988. The origin of Mhc class II gene polymorphism within the genus Mus. Nature 332: 651-654.

61. Klein, J. 1987. Origin of the major histocompatibility complex polymorphisms: The trans-species hypothesis. Hum. Immunol. 19: 155.

62. Hughes, A. and M. Nei. 1989. Nucleotide substitution at major histocompatibility complex class II Ioci: Evidence for overdominant selection. Proc. Natl. Acad. Sci. 86: 958-962.

63. Fan, W., M. Kasahara, J. Gutknecht, D. Klein, W.E. Mayer, M. Jonker, and J. Klein. 1989. Shared class II Mhc polymorphism between human and chimpanzees. Hum. Immunol. 26: 107.

64. Lawlor, D.A., F.E. Ward, P.D. Ennis, A.P. Jackson, and P. Parham. 1988. HLA-A and B polymorphism predate the divergence of human and chimpanzees. Nature 335: 268-271.

65. Parham, P., C.E. Lomen, D.A. Lawlor, J.P. Ways, N. Holmes, H.L. Coppin, R.D. Salter, A.M. Wan, and P.D. Ennis. 1988. Nature of polymorphism in HLA-A, -B, and -C molecules. Proc. Natl. Acad. Sci. 85: 4005-4009.

66. Parham, P., D.A. Lawlor, C.E. Lomen, and P.D. Ennis. 1989. Diversity and diversification of HLA-A,B,C alleles. $J$. Immunol. 142: 3937-3950.

67. Holmes, N. and P. Parham. 1985. Exon shuffling in vivo can generate novel class I molecules. EMBO J. 4: 2849-2854.

68. Hill, A.V.S., C.E.M. Allsopp, D. Kwiatkowski, N.M. Anstey, B.M. Greenwood, and A.J. McMichael. 1991. HLA class I typing by PCR: HLA-B27 and an African B27 subtype. Lancet 337: 640-642.

69. Landegren, U., R. Kaiser, J. Sanders, and L. Hood. 1988. A ligasemediated gene detection technique. Science 241: 1077-1080. 


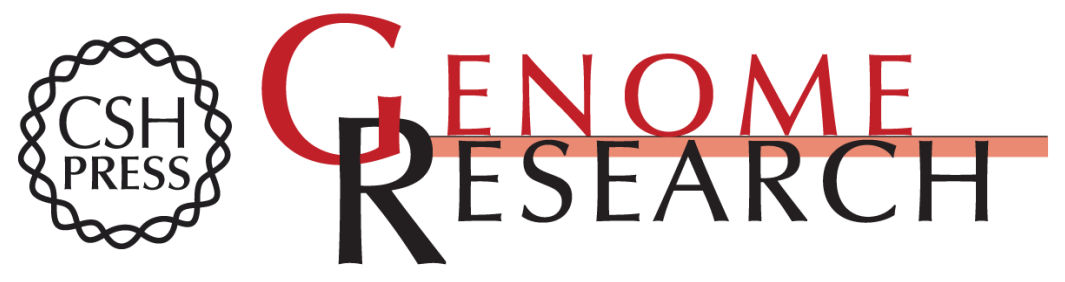

\section{PCR-based HLA class II typing.}

U Gyllensten and M Allen

Genome Res. 1991 1: 91-98

Access the most recent version at doi:10.1101/gr.1.2.91

References This article cites 64 articles, 20 of which can be accessed free at:

http://genome.cshlp.org/content/1/2/91.full.html\#ref-list-1

\section{License}

Email Alerting Receive free email alerts when new articles cite this article - sign up in the box at the Service top right corner of the article or click here.

\section{Affordable, Accurate Sequencing.}

To subscribe to Genome Research go to: https://genome.cshlp.org/subscriptions 